\title{
Editorials
}

\section{Prescribing statins in general practice:}

\author{
who decides?
}

GPs have been debating the pros and cons of statins for different patients since the 4S trial back in 1994 first showed that statins could reduce mortality from strokes and heart attacks in those with existing cardiovascular disease. ${ }^{1}$ The whole country seemed to be debating them in September 2016, with Rory Collins explaining on BBC Radio 4's Today programme that the benefits were 100 times the harms'. Collins had led a new review of the statins trials which concluded that the evidence strongly supported the benefits of statins and showed very modest risks. The review argued that 'exaggerated claims about side effects', often based on observational data, may have contributed to lower than recommended levels of statin use in individuals at increased risk of cardiovascular disease. ${ }^{2}$ Primary care data show that statin prescriptions are lower than recommended for high-risk groups. ${ }^{3}$

The arguments about the evidence have been well rehearsed, and it is hard to come to any other conclusion than that statin therapy has prevented a great many heart attacks and strokes in those with pre-existing cardiovascular disease. Important gaps remain, however, such as uncertainties over the long-term harms of statin therapy; the greater incidence of side effects such as muscle pain seen in clinical practice than reported in trials; the lack of trial data on the elderly lat least until the results of the STAREE study in the over-70s become available after 2020): ${ }^{4}$ and, importantly, the difficulty of comparing risk in trial populations with the output of risk calculators such as QRISK2, which is routinely used in UK general practice. It is also premature to dismiss large observational datasets that, despite the problem of residual confounding, can help fill some of the gaps left by trial evidence, such as the effects of statins over longer follow-up periods than the usual $3-5$ years seen in trials, and generalisability from trial participants to the general population in all its diversity.

\section{THE BENEFITS OF PRIMARY \\ PREVENTION ARE UNCERTAIN}

The benefits from primary prevention are less clear, with a reduction in cardiovascular disease (CVD) events, but no reduction in allcause mortality once those with pre-existing CVD are excluded. ${ }^{5}$ The US Preventive

even if new evidence fills all the evidence gaps at population level, there will always be huge uncertainties for the individual patient.

Services Task Force's (USPSTF) recent guidance on statin therapy recommended initiating use of low- to moderate-dose statins in adults aged 40 to 75 years without a history of CVD who have 1 or more CVD risk factors (dyslipidemia, diabetes, hypertension, or smoking) and a calculated 10 -year CVD event risk of $10 \%$ or greater. For people over 75 years, they concluded that the "current evidence is insufficient to assess the balance of benefits and harms!' This is similar to the National Institute for Health and Care Excellence (NICE) recommendation that GPs offer atorvastatin $20 \mathrm{mg}$ for the primary prevention of CVD to people who have a $10 \%$ or greater 10 -year risk of developing CVD. Estimate the level of risk using the QRISK2 assessment tool." Four out of five men over 50 years, and most women over 60 years, fall into this group in the UK.

This new guidance from the USPSTF is unlikely to make statin therapy any less contentious. In the UK, Rory Collins has complained about the BMJ to the UK's Committee on Publication Ethics, while Fiona Godlee (editor of the BMJ) has called for independent third-party scrutiny of the statins trial data to resolve the bitter and... unproductive' dispute. ${ }^{8}$

This spat might be entertaining to observe, were the subject matter not so important. The Global Burden of Disease programme estimated that cardiovascular disease is the single largest cause of death worldwide, responsible for 18 million deaths in 2015, and a growing proportion in the huge populations of China, India, and Brazil, where there have been few statins trials.

\section{EXPERTS' CONFLICT OF INTEREST}

The controversy is about science, but also about conflicts of interest and transparency, as the science about statins has been almost exclusively funded by an industry where a single drug (atorvastatin) made up to $€ 13$ billion per year, the marketing spend was vast, and industry funding for the clinical trials unit at Oxford has been reported as hundreds of millions of pounds. ${ }^{9}$ The Cholesterol Treatment Trialists' Collaboration (CTTC) hold the trial data, and have repeatedly ignored multiple calls to make them available for independent scrutiny. The CTTC's refusal to release the data makes for a slippery hold on the moral high ground of the statins debate, in view of the importance of the individual patient data to the health of the world's population. To many GPs it seems inexplicable, particularly now that most statins are off patent. And GPs are rightly cautious about blindly following the advice of experts, having had their fingers burnt in the past. Examples are the withdrawal of the COX-2 inhibitor rofecoxib after it had been prescribed to 80 million people, and the glitazone rosiglitazone, both of which were initially recommended in NICE guidance before being withdrawn.

But even if the data are eventually released for independent scrutiny, which they surely will be, and even if new evidence fills all the evidence gaps at population level, there

\section{"Real progress will have been made when the BBC Today programme discusses the proportion of people who have made an informed decision about taking statins, rather than how many are failing to comply with expert advice.}




\section{"Perhaps the most unfortunate aspect of the acrimonious statin debate is that it has hijacked conversations about reducing cardiovascular risk.}

will always be huge uncertainties for the individual patient. Evidence of effectiveness at population level can and does sit alongside overwhelming uncertainty at individual level. We need routine use of better patient decision aids even more than we need more extensive evidence of effectiveness in populations. NICE has produced an excellent decision aid for statins that includes clear information on harms and emphasises lifestyle changes: the choice is between continuing to make the changes to your lifestyle plus taking a statin, and just continuing with the changes to your lifestyle without also taking a statin. You can choose whether to take a statin or not..$^{10}$ The Mayo Clinic online statin decision aid is interactive and equally good, but both require more of the time that is already in very short supply in GP consultations."

The NICE decision aid shows that for every 100 people with a $10 \%$ risk of a cardiovascular event over 10 years who are taking atorvastatin, four people will be saved from developing coronary heart disease (CHD) or having a stroke, and 96 will receive no benefit $(90$ people will not develop CHD or have a stroke, but would not have done anyway, and six people will still develop CHD or have a stroke). It is not possible to predict what will happen to an individual person. Four in 100 is equivalent to a number needed to treat (NNT) of 25 over 10 years, which is generally not attractive for individuals. This compares with, for example, an NNT of 2 over 1 year for preventing ulcer recurrence with eradication therapy with proton pump inhibitors and antibiotics, and around 4 over 1 year for preventing chronic obstructive pulmonary disease exacerbations with salmeterol and fluticasone. The NICE decision aid also quantifies the harms from statin therapy, which are constant across all risk groups. For every 1000 people who take statins, over a year on average two of them will experience mild muscle pain, over 5 years three additional people will develop diabetes, and up to 1 in 10 will experience inflammation of the nasal passages, pain in the throat, nose bleed, allergic reactions, headache, nausea, constipation, wind, indigestion, or diarrhoea.

\section{FROM PATERNALISM TO INFORMED CHOICE}

In this context, the call from the CTTC experts that their advice should be followed more closely, with less debate and without independent review of the data, seems paternalistic. It does not resonate with GPs and patients in today's world, where transparency of evidence is the norm, and the role of doctors is often to help patents apply uncertain evidence to their particular context and make their own choices. ${ }^{12}$ Informed choice may result in some people choosing not to be prescribed statins, just as some people choose not to take their prescribed medication, eat unhealthy foods, exercise sub-optimally, or even smoke.

Perhaps the most unfortunate aspect of the acrimonious statin debate is that it has hijacked conversations about reducing cardiovascular risk. Increasing physical activity, stopping smoking, and eating more healthilyall reduce individual cardiovascular risk, while putting the person back in charge, rather than medicalising health and increasing dependency on doctors and drugs. Real progress will have been made when the BBC Today programme discusses the proportion of people who have made an informed decision about taking statins, rather than how many are failing to comply with expert advice.

\section{Nick Steel,}

Professor in Public Health, Norwich Medical School, Population Health and Primary Care, University of East Anglia, Norwich.

\section{Bob Fleetcroft,}

Honorary Senior Fellow, Norwich Medical School, Population Health and Primary Care, University of East Anglia, Norwich.

\section{Yasmeen Hassan,}

General Practice Specialty Trainee, Norwich Medical School, Population Health and Primary Care, University of East Anglia, Norwich.

\section{Provenance}

Commissioned; externally peer reviewed.

DOI: https://doi.org/10.3399/bjgp17X690953

\section{ADDRESS FOR CORRESPONDENCE}

\section{Nick Steel}

Norwich Medical School, Population Health and Primary Care, University of East Anglia, Norwich NR4 7TJ, UK.

\section{E-mail: n.steelduea.ac.uk}

\section{REFERENCES}

1. No authors listed. Randomised trial of cholesterol lowering in 4444 patients with coronary heart disease: the Scandinavian Simvastatin Survival Study (4S). Lancet 1994; 344(8934): 1383-1389.

2. Collins $R$, Reith $C$, Emberson J, et al. Interpretation of the evidence for the efficacy and safety of statin therapy. Lancet 2016; 388(10059): 2532-2561.

3. Gitsels LA, Kulinskaya E, Steel N. Survival benefits of statins for primary prevention: a cohort study. PLoS One 2016; 11(11): e0166847.

4. Zoungas S. A Clinical Trial of STAtin Therapy for Reducing Events in the Elderly (STAREE). 2016. https://clinicaltrials.gov/ct2/show/ NCT02099123 laccessed 28 Apr 2017).

5. Ray KK, Seshasai SR, Erqou S, et al. Statins and all-cause mortality in high-risk primary prevention: a meta-analysis of 11 randomized controlled trials involving 65,229 participants. Arch Intern Med 2010; 170(12): 1024-1031.

6. US Preventive Services Task Force, BibbinsDomingo K, Grossman DC, et al. Statin use for the primary prevention of cardiovascular disease in adults: US Preventive Services Task Force recommendation statement. JAMA 2016; 316(19): 1997-2007.

7. National Institute for Health and Care Excellence. Cardiovascular disease: risk assessment and reduction, including lipid modification. CG181. London: NICE, 2014 [updated 2016]. https://www.nice.org.uk/ guidance/cg181 (accessed 5 May 2017).

8. Hawkes N. BMJ editor asks chief medical officer to set up inquiry into statin risks and benefits. BMJ 2016; 354: i5046.

9. Wendling P. Statin safety claims in Lancet reignite acrimony, scientific divide. Medscape. com 2016; Sep 22: http://www.medscape. com/viewarticle/869125 laccessed $28 \mathrm{Apr}$ 2017).

10. National Institute for Health and Care Excellence. Patient decision aid. Taking a statin to reduce the risk of coronary heart disease and stroke. 2014. https://www.nice. org.uk/guidance/cg181/resources/patientdecision-aid-243780159 laccessed 28 Apr 2017)

11. Mayo Clinic. Statin choice decision aid. Welcome to the statin choice decision aid. https://statindecisionaid.mayoclinic.org/ laccessed 28 Apr 2017).

12. Gale NK, Greenfield S, Gill P, et al. Patient and general practitioner attitudes to taking medication to prevent cardiovascular disease after receiving detailed information on risks and benefits of treatment: a qualitative study. BMC Fam Pract 2011;12(1): 59. 